Original Article

\title{
Noninvasive ventilation on mortality of acute respiratory distress syndrome
}

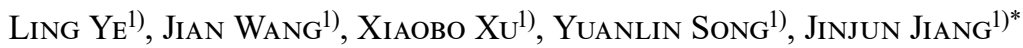 \\ 1) Department of Respiration Medicine, Fudan University, Zhongshan Hospital: Shanghai 200032, China
}

\begin{abstract}
Purpose] The aim of this study was to assess the efficacy of noninvasive ventilation (NIV) in acute respiratory distress syndrome (ARDS). [Subjects and Methods] The clinical data of 58 patients with ARDS that required mechanical ventilation in two intensive care units (ICU) was reviewed. [Results] Endotracheal intubation was performed in $55.17 \%$ of the total patients and in $39.53 \%$ of the patients who received NIV treatment. The APACHE II score for patients who only received IV was significantly higher than those who only underwent NIV $(25.67 \pm 5.30$ vs. $18.12 \pm 7.20)$. However, there were no significant differences in 28 -day/90-day survival rates, duration of mechanical ventilation, and length of ICU stay between these two groups. For patients from a NIV-to-IV group, the APACHE II scores before endotracheal intubation were higher than the scores from IV patients $(26.12 \pm$ 4.08 vs. $21.94 \pm 6.10$ ). The 90 -day survival rate in the NIV-to-IV group was significantly lower than that of the IVonly group (23.5\% vs. $73.3 \%$ ), although there was no difference in the 28 -day survival rate between the two groups. [Conclusion] The application of NIV reduces the percentage of patients requiring endotracheal intubation. Key words: Acute respiratory distress syndrome, Noninvasive ventilation, Intensive care units
\end{abstract}

(This article was submitted Jan. 28, 2016, and was accepted May 14, 2016)

\section{INTRODUCTION}

Acute respiratory distress syndrome (ARDS) is a major cause of acute respiratory failure and it is associated with high mortality and morbidity ${ }^{1}$. A range of physical methods for the general treatment of respiratory diseases is available ${ }^{2-6)}$. Among these methods, noninvasive ventilation (NIV) is a widely accepted treatment that has been used for diseases such chronic obstructive pulmonary disease exacerbation and cardiogenic pulmonary edema for more than 2 decades $^{7-9)}$. The advantages of NIV include no requirement for endotracheal intubation, which lowers the risk of ventilator-associated pneumonia, a shorter intensive care unit (ICU) length of stay, and decreased hospitalization costs ${ }^{10}$ ). However, the use of NIV for the treatment of ARDS is somewhat controversial. Agarwal et al. conducted a meta-analysis to assess the percentage of ARDS patients who were treated with NIV and required endotracheal intubation between 1995 and 2009, as well as the mortality rate of these patients ${ }^{11}$. Approximately $50 \%$ of the ARDS patients treated with NIV were spared from endotracheal intubation. Therefore, NIV can be used in selected patients, especially those presenting mild to moderate ARDS. However, some studies have indicated that once NIV fails, the prognosis becomes worse ${ }^{12,13)}$. Thus, the timing of subsequent IV may be critical.

Since there has been limited discussion of opposing viewpoints regarding the application of NIV for ARDS in the literature to date, we aim to help resolve any misunderstanding in the present study. Thus, we have performed a retrospective clinical study to assess the effect of NIV (performed according to a standardized procedure in our ICUs) on the prognosis of ARDS.

\section{SUBJECTS AND METHODS}

The clinical data of ARDS patients that required mechanical ventilation in either the ICU of the Department of Respiratory

\footnotetext{
*Corresponding author. Jinjun Jiang (E-mail: Jinjun_Jiang123@126.com)

(C2016 The Society of Physical Therapy Science. Published by IPEC Inc.

This is an open-access article distributed under the terms of the Creative Commons Attribution Non-Commercial No Derivatives (by-nc-nd) License $<$ http://creativecommons.org/licenses/by-nc-nd/4.0/>.
} 
medicine or the ICU of the Department of Surgery at Zhongshan Hospital affiliated with Fudan University between July 2005 and January 2007 was reviewed retrospectively.

All patients met the diagnostic criteria for ARDS proposed at the American-European Consensus Conference (AECC) in 1994 as follows: 1) acute onset; 2) partial pressure of arterial blood oxygen/fraction of inspired oxygen $\left(\mathrm{PaO}_{2} / \mathrm{FiO}_{2}\right) \leq 200$ $\mathrm{mmHg} ; 3$ ) bilateral infiltrates on frontal chest radiograph; and, 4) pulmonary artery wedge $\leq 18 \mathrm{mmHg}$ or no clinical evidence of left arterial hypertension ${ }^{14)}$. The exclusion/withdrawal criteria were as follows: 1) patients who were not suitable for NIV but rejected (or whose representatives rejected) endotracheal intubation; 2) patients who refused treatment; and, 3) patients who required early discharge from the hospital or transfer to another hospital. The study was approved by the ethics committee of Zhongshan hospital. Written informed consent was obtained from all patients.

In both ICUs, all the participating team members had previous experience with NIV. NIV was applied promptly after the patient was diagnosed as having ARDS. However, NIV was considered inappropriate for the following patients: 1) those unconscious or uncooperative; 2) those with increased airway secretion accompanied by decreased airway self-cleaning function; 3) those with upper gastrointestinal bleeding or heavy vomiting; 4) those with unstable hemodynamics; 5) those who could not wear an NIV mask due to face deformation, trauma, or surgery; 6) those who underwent tracheostomy; and, 7) those who experienced extubation failure after surgery.

At the start of NIV, the head of the bed was elevated to $30-45^{\circ}$ during ventilation to minimize the risk of aspiration. No patients were sedated at any stage during the NIV procedure. The patients received bilevel positive airway pressure (BiPAP) ventilation (BiPAP synchrony, Philips Respironics, Pittsburgh, USA) wearing oronasal masks. The initial positive end-expiratory pressure (PEEP) was $5 \mathrm{cmH}_{2} \mathrm{O}$ and the pressure support was adjusted to maintain a tidal volume of 6-10 ml/ $\mathrm{kg}$. The blood oxygen saturation $\left(\mathrm{SpO}_{2}\right) \geq 90 \%$ or $\mathrm{PaO}_{2} \geq 60 \mathrm{mmHg}$ was achieved through the adjustment of $\mathrm{PEEP}$ and $\mathrm{FiO} \mathrm{O}_{2}$. The procedures were performed as follows: a) PEEP was initially set at $5 \mathrm{cmH}_{2} \mathrm{O}$, and $\mathrm{FiO}_{2}$ was increased gradually to achieve the goal of $\mathrm{SpO}_{2} \geq 90 \%$ or $\mathrm{PaO}_{2} \geq 60 \mathrm{mmHg}$; b) When $\mathrm{FiO}_{2}$ reached $60 \%$ but $\mathrm{SpO}_{2}$ or $\mathrm{PaO}_{2}$ did not meet the requirement, PEEP was gradually increased in increments of 2-3 $\mathrm{cmH}_{2} \mathrm{O}$; and, c) When PEEP reached $10 \mathrm{cmH}_{2} \mathrm{O}_{\text {but }} \mathrm{SpO}_{2}$ or $\mathrm{PaO}_{2}$ still did not meet the requirement, then $\mathrm{FiO}_{2}$ was further increased. The vital signs of the patients were closely monitored at all times during this procedure.

In patients presenting conditions inappropriate for NIV, IV was applied immediately with the written agreement of the patient or their representative. In addition, if: 1) $\mathrm{SpO}_{2}<90 \%$ or $\mathrm{PaO}_{2}<60 \mathrm{mmHg}$ continuing for over 1 hour or, 2) the conditions were otherwise deemed inappropriate for NIV, then the ventilation procedure in that patient was changed from NIV to endotracheal intubation.

The invasive ventilation (IV) patients received pressure-controlled mechanical ventilation modalities ( $\mathrm{p}$-SIMV or BiPAP). Two types of mechanical ventilators were used (without preference): VELA (VIASYS, Palm Springs, USA) and Savina (Drager, Lubeck Germany). The standardized procedures were as follows: a) Lung protective mechanical ventilation was performed with inspiratory pressure (i.e. platform pressure) set at $\leq 30 \mathrm{cmH}_{2} \mathrm{O}$; b) $\mathrm{SpO}_{2} \geq 90 \%$ or $\mathrm{PaO}_{2} \geq 60 \mathrm{mmHg}$ was achieved through the adjustment of PEEP (setting range, 5-15 $\mathrm{cmH}_{2} \mathrm{O}$ ) and $\mathrm{FiO}_{2}$; c) While maintaining lung protective ventilation and appropriate PEEP, the tidal volume was increased to $8-10 \mathrm{ml} / \mathrm{kg}$ (standard body weight) through the adjustment of inspiratory pressure; d) When a tidal volume of 8-10 $\mathrm{ml} / \mathrm{kg}$ could not be achieved, a smaller tidal volume ventilation (6-8 ml/kg) was permitted; e) To improve patient-ventilator synchronization, a sedative (midazolam) and/or muscle relaxant (vecuronium bromide) was used; f) When $\mathrm{FiO}_{2} \leq 40 \%$ and $\mathrm{PEEP} \leq 5 \mathrm{cmH}_{2} \mathrm{O}$ were achieved, the patient was gradually weaned from mechanical ventilation, and a spontaneous breathing trial (SBT) was performed before fully withdrawing ventilatory support; and g) Extubation was performed for patients who were successfully withdrawn from the ventilator.

The following clinical information was collected: sex; age; primary diagnosis; risk factors, including hypertension and diabetes; Acute Physiology and Chronic Health Evaluation II (APACHE II) scores when patients were diagnosed with ARDS; whether endotracheal intubation was performed on patients with NIV; vital signs; arterial blood gases; duration of mechanical ventilation; the length of ICU stay; 28-day survival; 90-day survival.

The Statistical Package for the Social Sciences (SPSS) version 17.0 software (SPSS Inc., Chicago, IL, USA) was used for statistical analysis. Independent t-tests were used to compare the means between 2 groups. One-way analysis of variance (ANOVA) was used to compare the means between multiple groups. When a significant difference was present, pairwise comparisons using the LSD method were conducted. A paired-sample t-test was used to compare the means from the same set of patients before and after the intervention was performed. The chi-square test was used for categorical variables, and if a significant difference was detected, this test was expanded for pairwise comparisons and the significance level was adjusted appropriately $(\alpha=0.05 /$ number of comparisons; number of comparisons $=n(n-1) / 2)$. Kaplan-Meier survival curves were plotted and the log rank test was used for comparisons between the survival curves.

\section{RESULTS}

A total of 72 patients with ARDS were screened and 58 were included. Forty-three patients received NIV as the first choice of treatment, however, NIV was changed to IV in 17 patients according to the standardized procedure of our ICUs. Moreover, IV was applied to 15 patients as first-line therapy.

The APACHE II scores of the patients in the IV group were significantly higher than those of the patients in the NIV 
Table 1. General characteristics of the initial 2 groups of ventilator-treated patients

\begin{tabular}{lcc}
\hline & $\begin{array}{c}\text { Noninvasive } \\
(\mathrm{n}=43)\end{array}$ & $\begin{array}{c}\text { Invasive } \\
(\mathrm{n}=15)\end{array}$ \\
\hline Age (years) & $54.2 \pm 18.9$ & $62.1 \pm 13.9$ \\
Males/Females & $26 / 17$ & $11 / 4$ \\
Etiology of ARDS & $27 / 16$ & $8 / 7$ \\
(pulmonary/extrapulmonary) & & \\
$\mathrm{PaO}_{2} / \mathrm{FiO}_{2}$ (mmHg) & $130.4 \pm 45.5$ & $110.7 \pm 37.8$ \\
$\mathrm{APACHE} \mathrm{II} \mathrm{score*}_{\text {Hypertension }(\%)}$ & $19.6 \pm 7.0$ & $25.7 \pm 5.3$ \\
Diabetes (n) & $14(32.6 \%)$ & $4(26.7 \%)$ \\
\hline
\end{tabular}

$* \mathrm{p}<0.05$

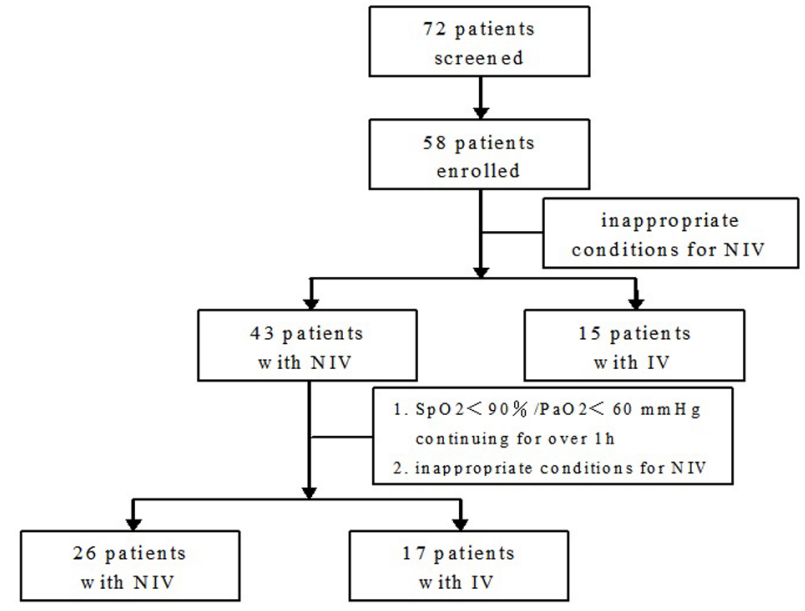

Fig. 1. Flow chart of patients' screening and enrollment

group, which indicated that the severity of disease of IV patients was higher than that of NIV patients. However, there were no significant differences in age, gender, cause of disease, and $\mathrm{PaO}_{2} / \mathrm{FiO}_{2}$ ratio between the 2 groups (Table 1). There were 17 patients who were assigned to the NIV group but eventually changed to endotracheal intubation. The duration of NIV treatment for these patients was $5.29 \pm 4.92$ days. Endotracheal intubation was ultimately performed in $39.53 \%$ of the patients in the NIV group and $55.17 \%$ of the total patient cohort. The patients were further divided into 3 groups: the IV-only group (patients who only received IV), the NIV-only group (patients who only received NIV), and the NIV-to-IV group (patients who first received NIV but subsequently required IV). The APACHE II scores of the IV-only group were significantly higher than those of the NIV-only group $(25.67 \pm 5.30$ vs. $18.12 \pm 7.20)$, though there were no significant differences between the APACHE II score of the NIV-to-IV group and those of the other 2 groups (Fig. 1). This result indicated that the severity of disease for patients in the NIV-to-IV group was within the same range as patients assigned to the other 2 groups. There were no significant differences in age, gender, cause of disease, and $\mathrm{PaO}_{2} / \mathrm{FiO}_{2}$ ratio among these 3 groups (Table 2).

For the NIV-to-IV group, APACHE II scores were collected when patients were diagnosed with ARDS and also when endotracheal intubation was performed. The latter scores were significantly higher than the former $(26.12 \pm 4.08 \mathrm{vs}$. 21.94 $\pm 6.10, \mathrm{p}=0.002$ ), indicating that the condition of patients in the NIV-to-IV group progressively worsened. Moreover, there were no significant differences in APACHE II scores between the NIV-to-IV group and IV-only group (26.12 \pm 4.08 vs. 25.67 $\pm 5.30, \mathrm{p}=0.832$ ) after endotracheal intubation had been performed on patients.

There were significant differences between the 3 groups in the 90-day survival rate, but not in the 28-day survival rate, duration of mechanical ventilation, or ICU length of stay (Table 3). Further analysis indicated that significantly more patients in the IV-only group (compared to those of the NIV-to-IV group) survived for 90 days $(\mathrm{p}=0.005$ ). The survival curves also demonstrated that the 90-day cumulative survival rate of the IV-only group was significantly higher than that of the NIV-toIV group $(\mathrm{p}=0.016)$.

When an NIV-treated patient required IV, the oronasal mask was removed and endotracheal intubation was performed. Dynamic monitoring of $\mathrm{SpO}_{2}$ was conducted to compare the lowest $\mathrm{SpO}_{2}$ within the 5 minute period before the removal of the oronasal mask $(88.29 \pm 2.23)$ and the lowest $\mathrm{SpO}_{2}$ during endotracheal intubation $(73.65 \pm 4.90)$. According to this result, $\mathrm{SpO}_{2}$ decreased significantly during endotracheal intubation. Thus, endotracheal intubation can increase the severity of hypoxia of patients treated with NIV.

\section{DISCUSSION}

The use of NIV for the treatment of ARDS remains controversial. The present study has demonstrated that approximately half of our patients were spared from endotracheal intubation through application of NIV. This result is similar to that reported in the meta-analysis performed by Agarwal et $\mathrm{al}^{11)}$. However, further analyses revealed that the severity of the disease was significantly higher in patients who received IV only compared with patients who underwent NIV only, although there were no significant differences in the 28-day survival rate, 90-day survival rate, duration of mechanical ventilation, or ICU length of stay between these 2 groups.

At the onset of ARDS, the severity of disease was milder in the NIV-to-IV patients compared with those who received IV only. With the progression of the disease, there was no significant difference in APACHE II scores between the NIV-to-IV group and the IV-only group before endotracheal intubation. However, the 90-day survival rate of the NIV-to-IV group was significantly lower than that of the IV-only group. Although the 28-day survival rate of the NIV-to-IV group was also lower 
Table 2. General characteristics of the final three groups of ventilator-treated patients

\begin{tabular}{lccc}
\hline & $\begin{array}{c}\text { Noninvasive only } \\
(\mathrm{n}=26)\end{array}$ & $\begin{array}{c}\text { Noninvasive to invasive } \\
(\mathrm{n}=17)\end{array}$ & $\begin{array}{c}\text { Invasive only } \\
(\mathrm{n}=15)\end{array}$ \\
\hline Age (years) & $51.9 \pm 18.5$ & $57.9 \pm 19.4$ & $62.1 \pm 13.9$ \\
Males/Females & $17 / 9$ & $9 / 8$ & $11 / 4$ \\
Etiology of ARDS (pulmonary/extrapulmonary) & $17 / 9$ & $10 / 7$ & $8 / 7$ \\
$\mathrm{PaO}_{2} / \mathrm{FiO}_{2}$ (mmHg) & $135.6 \pm 41.6$ & $122.4 \pm 51.3$ & $110.7 \pm 37.8$ \\
$\mathrm{APACHE} \mathrm{II}$ score* & $18.1 \pm 7.2^{\dagger}$ & $21.9 \pm 6.1$ & $25.7 \pm 5.3^{\dagger}$ \\
Hypertension (\%) & $8(30.8 \%)$ & $6(35.3 \%)$ & $4(26.7 \%)$ \\
Diabetes (n) & $8(30.8 \%)$ & $2(11.8 \%)$ & $1(6.7 \%)$ \\
\hline
\end{tabular}

${ }^{*} \mathrm{p}<0.05 ;{ }^{\dagger}$ There was a significant difference between the 2 groups, $\mathrm{p}=0.001$

Table 3. Outcomes of the three groups of ventilator-treated patients

\begin{tabular}{lccc}
\hline & $\begin{array}{c}\text { Noninvasive only } \\
(\mathrm{n}=26)\end{array}$ & $\begin{array}{c}\text { Noninvasive to invasive } \\
(\mathrm{n}=17)\end{array}$ & $\begin{array}{c}\text { Invasive only } \\
(\mathrm{n}=15)\end{array}$ \\
\hline Survived for 28 days (\%) & $15(57.69 \%)$ & $6(35.29 \%)$ & $11(73.33 \%)$ \\
Survived for 90 days (\%)* & $14(53.85 \%)$ & $4(23.53 \%)^{\dagger}$ & $11(73.33 \%)^{\dagger}$ \\
Duration of mechanical ventilation & $11.8 \pm 10.3$ & $19.1 \pm 23.3$ & $13.9 \pm 11.9$ \\
ICU length of stay & $26.4 \pm 18.3$ & $23.9 \pm 30.2$ & $24.1 \pm 26.7$ \\
\hline
\end{tabular}

${ }^{*} \mathrm{p}<0.05$; ${ }^{\dagger}$ There was a significant difference between the 2 groups, $\mathrm{p}=0.005$ (adjusted significance level: $\alpha=0.017$ )

than that of the IV-only group (35.29\% vs. $73.33 \%)$, this difference was not statistically significant. Upon analysis of our results, it is apparent that instead of reducing ARDS mortality rates, patients' prognoses were worsened when endotracheal intubation had to be performed as a consequence of failure of NIV (according to our standardized procedure). Several previous studies have also indicated that the mortality rates of patients who experienced NIV failure were higher than that of those who did not receive NIV ${ }^{11,12}$. Moreover, Schnell et al. proposed that NIV failure was an independent risk factor for mortality ${ }^{9}$.

Although NIV possesses distinct advantages, an airtight seal between the airway device and the airway of the patient is difficult to achieve. The consequent air leakage will result in hypoventilation, flatulence, and respiratory secretion expectoration difficulties. In addition, NIV has the disadvantage of a lack of patient-ventilator desynchronization. These factors play a negative role in the application of NIV in ARDS patients. Once NIV fails and endotracheal intubation has to be performed, serious hypoxemia may occur. Indeed, according to our study, endotracheal intubation under these circumstances can significantly increase the severity of hypoxia, thus rendering the condition of the patient even worse. Furthermore, according to a study by Delclaux et al., cardiac arrest can occur during endotracheal intubation in continuous positive airway pressure therapy due to hypoxia ${ }^{15)}$.

Three randomized controlled trials have been published that have assessed the effect of NIV on ARDS ${ }^{12,16,17)}$. According to the results of these studies, the percentage of patients requiring endotracheal intubation in the NIV group and the subsequent mortality rate were not lower than those in the high-concentration oxygen group. Therefore, Agarwal et al. proposed that NIV should be used only in carefully selected ARDS patients admitted to the ICU, and that close monitoring of the patient's condition should be performed ${ }^{11)}$. Antonelli et al. reported that a simplified acute physiology score II (SAPS II) $>34$ and $\mathrm{PaO}_{2} / \mathrm{FiO}_{2} \leq 175$ after $1 \mathrm{~h}$ of NIV were independently associated with NPPV failure and the need for endotracheal intubation $^{12)}$. According to Yoshida et al., an APACHE II score $>17$ and a respiratory rate $>25 / \mathrm{min}$ after $1 \mathrm{~h}$ of NIV are predictive factors for the need for endotracheal intubation ${ }^{18)}$. In a study reported by Thille et al., NIV was attempted in ARDS patients with $\mathrm{PaO}_{2} / \mathrm{FiO}_{2}>150^{19)}$. However, intubation was required in $84 \%$ of severe ARDS cases and NIV had potential deleterious effects in these patients. Overall, the high mortality rate reported suggests a cautious approach to NIV use in patients with ARDS; with recommendations including early initiation, intensive monitoring, and prompt intubation if signs of NIV failure emerge ${ }^{20}$.

Since a majority of ARDS patients suffer from serious hypoxia or multiple organ failure, invasive ventilation remains the first choice treatment strategy for these patients. However, additional prospective studies are needed to determine whether NIV is more suitable for some candidates. The present study was limited by its small sample size. Therefore, studies with larger sample sizes are also needed for further evaluation of the efficacy of NIV in the treatment of ARDS.

In our study comprising 58 patients with ARDS, application of NIV reduced the percentage of patients requiring endotracheal intubation, but it did not decrease the mortality rate of ARDS patients. Furthermore, in cases where NIV failed and the patient required endotracheal intubation, the prognosis was even worse (using the standardized procedure of NIV in our ICUs.) Overall, NIV should be used only in carefully selected ARDS patients. 


\section{ACKNOWLEDGEMENTS}

This work was supported by the National Natural Science Foundation of China (81073111) and Jiangsu College's Advantages of Discipline construction funded projects (Nzyzyxjg-1006).

\section{REFERENCES}

1) Modrykamien AM: Gupta P1: The acute respiratory distress syndrome. Proc, 2015, 28: 163-171.

2) Lee Y, Kim J, Jin Y: The efficacy of pulmonary rehabilitation using a mechanical in-exsufflator and feedback respiratory training for cervical cord injury patients. J Phys Ther Sci, 2012, 24: 89-92. [CrossRef]

3) Roh H, Lee D, Lee S, et al.: Respiratory muscle training of pulmonary function for smokers and non-smokers. J Phys Ther Sci, 2012, 24: 691-693. [CrossRef]

4) Kamide N, Ogino M, Sumida S, et al.: Relationships between dyspnea, respiratory muscle strength, and ventilatory failure in patients with amyotrophic lateral sclerosis. J Phys Ther Sci, 2007, 19: 223-225. [CrossRef]

5) Yi SJ, Kim JS: The effects of respiratory muscle strengthening exercise using a sling on the amount of respiration. J Phys Ther Sci, 2015, 27: 2121-2124. [Medline] [CrossRef]

6) Higashijima M: Relationship between swallowing dysfunction and decreased respiratory function in dementia patients. J Phys Ther Sci, 2013, 25: 941-942. [Medline] [CrossRef]

7) Perner A, Citerio G, Bakker J, et al.: Year in review in Intensive Care Medicine 2014: II. ARDS, airway management, ventilation, adjuvants in sepsis, hepatic failure, symptoms assessment and management, palliative care and support for families, prognostication, organ donation, outcome, organisation and research methodology. Intensive Care Med, 2015, 41: 389-401. [CrossRef]

8) Mariani J, Macchia A, Belziti C, et al.: Noninvasive ventilation in acute cardiogenic pulmonary edema: a meta-analysis of randomized controlled trials. J Card Fail, 2011, 17: 850-859. [Medline] [CrossRef]

9) Schnell D, Timsit JF, Darmon M, et al.: Noninvasive mechanical ventilation in acute respiratory failure: trends in use and outcomes. Intensive Care Med, 2014, 40: 582-591. [Medline] [CrossRef]

10) Brochard L, Mancebo J, Elliott MW: Noninvasive ventilation for acute respiratory failure. Eur Respir J, 2002, 19: 712-721. [Medline] [CrossRef]

11) Agarwal R, Aggarwal AN, Gupta D: Role of noninvasive ventilation in acute lung injury/acute respiratory distress syndrome: a proportion meta-analysis. Respir Care, 2010, 55: 1653-1660. [Medline]

12) Antonelli M, Conti G, Esquinas A, et al.: A multiple-center survey on the use in clinical practice of noninvasive ventilation as a first-line intervention for acute respiratory distress syndrome. Crit Care Med, 2007, 35: 18-25. [Medline] [CrossRef]

13) Demoule A, Girou E, Richard JC, et al.: Benefits and risks of success or failure of noninvasive ventilation. Intensive Care Med, 2006, 32: 1756-1765. [Medline] [CrossRef]

14) Bernard GR, Artigas A, Brigham KL, et al. Consensus Committee: Report of the American-European Consensus conference on acute respiratory distress syndrome: definitions, mechanisms, relevant outcomes, and clinical trial coordination. J Crit Care, 1994, 9: 72-81. [Medline] [CrossRef]

15) Delclaux C, L'Her E, Alberti C, et al.: Treatment of acute hypoxemic nonhypercapnic respiratory insufficiency with continuous positive airway pressure delivered by a face mask: a randomized controlled trial. JAMA, 2000, 284: 2352-2360. [Medline] [CrossRef]

16) Antonelli M, Conti G, Bufi M, et al.: Noninvasive ventilation for treatment of acute respiratory failure in patients undergoing solid organ transplantation: a randomized trial. JAMA, 2000, 283: 235-241. [Medline] [CrossRef]

17) Ferrer M, Esquinas A, Leon M, et al.: Noninvasive ventilation in severe hypoxemic respiratory failure: a randomized clinical trial. Am J Respir Crit Care Med, 2003, 168: 1438-1444. [Medline] [CrossRef]

18) Yoshida Y, Takeda S, Akada S, et al.: Factors predicting successful noninvasive ventilation in acute lung injury. J Anesth, 2008, 22: 201-206. [Medline] [CrossRef]

19) Thille AW, Contou D, Fragnoli C, et al.: Non-invasive ventilation for acute hypoxemic respiratory failure: intubation rate and risk factors. Crit Care, 2013, 17: R269. [Medline] [CrossRef]

20) Nava S, Schreiber A, Domenighetti G: Noninvasive ventilation for patients with acute lung injury or acute respiratory distress syndrome. Respir Care, 2011, 56: 1583-1588. [Medline] [CrossRef] 